\title{
Meconium aspiration syndrome
}

INSERM

\section{Source}

INSERM. (1999). Orphanet: an online rare disease and orphan drug data base. Meconium aspiration syndrome. ORPHA:70588

Meconium aspiration syndrome is a pulmonary complication appearing in newborns with a meconium-stained amniotic fluid. Aspirated meconium can interfere with normal breathing by several mechanisms including airway obstruction, chemical irritation, infection and surfactant inactivation and induces more or less severe signs of respiratory distress at birth. 